\title{
Designing Tasks For Math Modeling In College Algebra: A Critical Review
}

Susan Staats, University of Minnesota, USA

Douglas Robertson, University of Minnesota, USA

\begin{abstract}
Over the last decade, the pedagogical approach known as mathematical modeling has received increased interest in college algebra classes in the United States. Math modeling assignments ask students to develop their own problem-solving tools to address non-routine, realistic scenarios. The open-ended quality of modeling activities creates dilemmas for teachers who design the assignments and convey grading expectations to students. This article provides a critical review of our own approach to task design for modeling as well as the extensive contributions in the United Kingdom (UK) and elsewhere in Europe dating from the 1980s and 1990s. Each approach attends differently to several competing needs: modeling as a process, modeling competencies, and developing clarity in academic writing. These resources provide substantial support for instructors of college algebra and other early undergraduate mathematics classes in the U.S. who may be embarking for the first time on task design and grading in a modeling framework.
\end{abstract}

Keywords: College Algebra; Modeling; Task Design

\section{INTRODUCTION}

$\mathrm{n}$ the United States, early undergraduate mathematics curriculum, particularly college algebra, is widely criticized in terms of both the quality of learning afforded students and students' success rates (Complete College America, 2012; Gordon, 2008; Herriott \& Dunbar, 2009; Small, 2002, 2006). Addressing the problem requires changes at multiple levels, from precollege preparation to course pathways at college. In this article, we discuss a pedagogical recommendation known as mathematical modeling, in which the teacher poses non-routine, complex or realistic scenarios, requiring students to create their own mathematical solution methods. Each student or student group may develop a unique approach and answer. The modeling approach can support student achievement in mathematics because it allows students to rely on parts of mathematics that they understand, and because it emphasizes critical, independent thinking.

Students usually submit their modeling work as a mathematical essay with verbal explanation alongside mathematical work. This written format combined with variety in solution method means that college algebra teachers who adopt a modeling approach must develop an assignment structure and a grading method that is quite different and more complex than typical marking of abstract mathematical problems. In this article we discuss a modeling assignment framework that has been used in our own college algebra modeling class since 2008. We provide a critical comparison of our approach with assignment and assessment statements that were developed in the early years of modeling pedagogy in Europe. As more college algebra math classes adopt modeling pedagogy in the United States, instructors may benefit from reviewing these approaches to modeling task design.

\section{LITERATURE REVIEW: FROM LEARNING PROCESS TO TASK DESIGN}

\section{The Modeling Process}

Over the past 15 years, college algebra textbooks based on modeling have become available for higher education in the United States (Rockswold, 2009; Timmons, Johnson, \& McCook, 2008). While math modeling has entered the early undergraduate mathematics curriculum in the U.S. rather recently, some postsecondary and 
secondary classrooms incorporated modeling pedagogies as early as the mid-1980s in the UK and elsewhere in Europe. An early issue in modeling pedagogy was to distinguish activities in which students learn to work with recognized models and applications, and those in which students construct their own methods. This distinction was termed "learning models" versus "learning modeling" (Burkhardt, 1984). As Berry and Le Masurier (1984) put it, it is "the modeling process that is being assessed not the model" (p. 58, original italics). This difference poses dilemmas for instructors who must create problem statements that communicate expectations and grading methods clearly.

The modeling process is often presented diagrammatically as the movement in stages between the "real world" and "mathematics." In Figure 1, we offer a version based on Maa $\beta$ (2006), but similar perspectives are reported at least as early as 1981 (Open University, 1981 in Mason, 1984, p. 194). The stages are simplifying, mathematizing, working within mathematics, interpreting and validating. Some versions of the modeling process also include a stage of writing up the report (Haines \& Crouch, 2007). Blomhøj and Jensen (2007) presented similar mathematical activities through a different diagram, the KOM flower. By simplifying, students decide on assumptions and the relevance of available information, establishing a limited version of the original scenario that better lends itself to mathematical activity. In the mathematizing stage, students identify relationships between variables and choose a system of notation; for example, graphing, equations, diagrams, or tables of values. In the third stage, working within the mathematics, students may discover that they need to solve several smaller problems, but in any case, they will use their knowledge of traditional mathematics to reach an answer to the original question. The interpretation stage asks students to express their answer in the terms of the original, non-mathematical context and to create a generalized solution to the problem. The validating stage requires students to reflect on whether their answers are reasonable, and to embark on a new cycle of modeling in order to refine their method and their solutions.

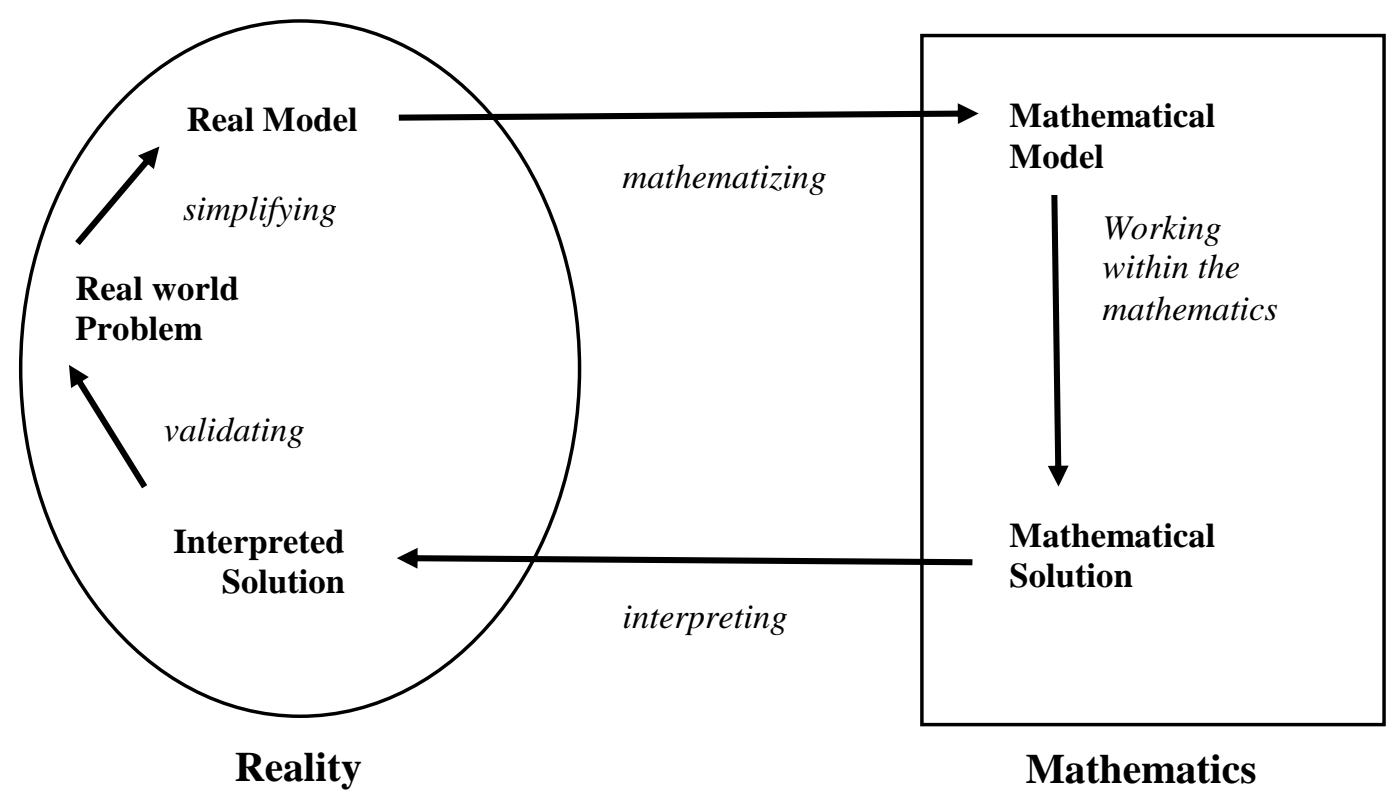

Figure 1: The Modeling Process (adapted from Maaß, 2006, p. 115)

Lesh, Cramer, Doerr, Post, and Zawojewski (2003) presented a perspective on the modeling process that focuses on the pedagogical teaching sequence rather than on the competencies that students must acquire. In their view, modeling begins with warm-up activities for students. For example, if students use manipulatives, they should have time to simply play with them in order to learn their properties. Then they are presented with a scenario, or a Model-Eliciting Activity (MEA), that is designed to create a need within the students to solve a problem. Students later elaborate and generalize their model. Students often complete an MEA by writing a letter to a client detailing their solution, preferably in a generalized form. 


\section{Approaches to Designing Modeling Assignments}

From the 1980s, scholars in the UK and in Europe grappled with issues of designing assignments and grading methods to guide both students and instructors. On one hand, assignments responded to the emerging understanding of modeling as a distinctive and complex mathematical activity. On the other hand, the literature expresses a concern for establishing academic writing standards that require students to convey modeling solutions in a professional manner. To some extent, these two concerns are at odds. Professional writing tends to present ideas in a linear fashion; for example, placing methods before conclusions. Modeling involves successive cycles of revision and refinement, so that one's best method might take place after reaching conclusions about a preliminary method. Each approach to designing modeling assignments recognizes this tension between modeling process and academic writing, but may emphasize one more than another.

Since 1971, the UK's Open University has provided distance education to adult students (Berry \& Le Masurier, 1984). Their introduction of mathematical modeling curriculum in 1982 was notably ambitious. Students completed modeling assignments without the support of a classroom teacher or peer group. Student projects were graded by part-time tutors who were engaged as full-time lecturers and professors in other postsecondary institutions. Clarity of expectation and consistency of grading were therefore prominent concerns in developing modeling write-up guides (Berry \& Le Masurier, 1984). Berry and Le Masurier commented on several issues that may be useful to instructors setting up a math modeling class: an outline of their teaching sequence, a marking scheme for an initial, small scale modeling project, and a marking scheme for a more substantial modeling project. Their assignment for the longer modeling project can be seen as a framework for a mathematical writing genre that incorporates elements of the modeling process. The structure and point values for students' submissions are as follow (summary based on Berry \& Le Masurier, 1984, p. 58):

1. Abstract (5 points): Include a statement of the original problem, the conclusion, and its significance. Indicate data sources.

2. Formulation (5 points): State assumptions, simplifications, and other features of the problem scenario.

3. Initial Model (30 points): Define variables, give the model and the solution. Interpret and critique the initial model.

4. Data (10 points): Explain how data was collected and its relevance. Devise a clear way of presenting the data.

5. Revised Model (20 points): Present revised models, explaining how they respond to criticism in stage 3. Present and criticize final model.

6. Conclusions (10 points): Summarize the outcome of the modeling assignment.

The assignment is structured to assess the students' process of modeling, not whether they achieve a professionally useful model. In this task design, process is emphasized by requiring student description of both an initial model and revised models, with the initial model receiving the most points. Process skills such as taking a critical perspective, summarizing, and reflection are required at several points in the submission.

In an approach from the same era, Hall (1984) asserted that numerous mathematical modeling sub-skills can be subsumed within three categories of a written submission: content, presentation, and drive. Content refers to the ability to process experimental data, define variables, note patterns, create and solve math models. Presentation involves the representation of data, transferring data to pictorial form, and the ability to write clearly. Drive involves a wide range of higher-order thinking including the ability to formulate problems, consult sources for information, revise and interpret the model, work productively in a group and whether the project was "tackled vigorously or reluctantly" (p. 145). Hall reported that his point values for the categories of content, presentation, and drive were in a 2:2:1 ratio. The weighting system reflects the dilemma that although drive represents abilities with substantial professional value, its marking is subjective.

In the early 1990s, the UK-based Assessment Research Group (ARG) held a series of workshops on assessing student projects, mostly involving higher education faculty (Haines \& Houston, 2001). The group was active during 1991 to 1996 when they worked on developing assessment rubrics for student projects. They scored student sample projects together, and used this process to revise their rubric and marking scheme (Houston, Haines, 
\& Kitchen, 1994). They also separated their rubrics into topic-specific ones: for student poster presentations (Berry \& Houston, 1996), oral presentations (Le Masurier \& Crouch, 1996), and for written mathematics projects (Berry \& Davies, 1996). Written project rubrics included pure mathematics, statistics and modeling, and statistics and involved rating competencies on a four-point scale from High to Low, along with Not Shown and Not Applicable. Although space limitations do not allow us to reproduce the rubrics here, they will be extremely useful for other instructors incorporating open inquiry projects into their own classrooms; Crouch (1996) provided a report on these efforts. The assignment format on modeling appears to be a refinement of the one developed at the Open University. It requires grading in 11 categories:

- $\quad$ states objectives of task
- $\quad$ identifies the main features of the task
- $\quad$ identifies possible variables of interest
- $\quad$ statos mathematical problem
- $\quad$ inds solution
- $\quad$ interprets solution
- $\quad$ shows evidence of research
- $\quad$ demonstrates initiative, determination and flair

(Berry \& Davies, 1996, p. 3.7)

The ARG version of a modeling assignment represents an intensive effort to improve consistency of grader scoring. Here, though, the cyclic revisions of the modeling process are less prominent. Reporting both an initial and refined model is no longer required. The ARG version takes on a more linear narrative character with more emphasis on academic skills like conducting background research. Instructors new to modeling projects will have to make similar decisions on whether to weight more strongly mathematical process or professional writing standards.

\section{OUR APPROACH TO MODELING ASSIGNMENTS}

Every assignment expresses the pedagogical values of the teacher. We designed our assignment framework to help students develop process skills by focusing on the stages of modeling. We also wanted students to refine and generalize their models, as emphasized in literature on MEAs. We planned to use a similar task framework, with minor modifications, throughout all class modeling activities. Finally, we wanted to honor variety in student solution approach and to reward creativity and ambition. The guide that we developed asks students to submit work in terms of the five stages: simplify, represent, solve, interpret, and extend. At the time, we were not familiar with the task design efforts of 30 years ago, but because the framework is structured around recognized modeling competencies, our approach represents a view of the learning process that is consistent with earlier approaches.

Figure 2 provides a sample task assignment for an easy, accessible modeling activity that Staats uses on the first day of her college algebra class. In this "Calendar Game" model, student pairs receive handouts consisting of 1 month of a calendar. One student secretly selects a square of adjacent dates on the calendar, for example, dates 17, 18,24 , and 25 , and tells the other student the sum of the dates, "The sum is 84 ." The second student must find a method to determine the four dates that generate the sum. Students are encouraged to begin with a guess and check method using the calendar handout, but to move towards a method that does not require looking at a calendar. While this particular assignment terminates in a single, correct solution, it is a useful first model because it reveals a great deal about students' level of algebra knowledge and their degree of comfort with problem-solving. Because it is a game, it helps students meet their classmates; it also provides the opportunity for students to conduct a relatively easy model write-up for their first try. Each modeling activity uses a similar write-up guide, with slight modifications. In models that require direct measurements, for example, the simplify section questions will directly request the units and methods of measurement, along with assumptions of the model. One such model asks students to use plastic cylinders of different lengths and diameters to model the relationship between size of image and distance to wall. Some of our most challenging models are adaptations of the Consortium for Mathematics and Its 
Applications (COMAP; 2013) high school contest in modeling. Contest questions from past years provide low ceiling, algebra-appropriate tasks that afford nearly unlimited potential for mathematical work. A contest question that was revised for local relevance is to design a bike sharing business for the city of St. Paul, Minnesota. Another modified contest question was to study data on Minnesota graduation rates, crime, juvenile detention, and unemployment statistics and to create an argument for priorities for community improvement. Additional sources of modeling problems are provided by the University of Minnesota (n.d.) and the Purdue University School of Engineering (2013).

\footnotetext{
The Calendar Game

Simplify

The simplify stage of modeling involves defining variables; explaining measurements; discussing domains, ranges, or logical limits of the variables; and listing assumptions that you need to make in order to apply math to a real-world question. 6 points.

a) If you used variables like $\mathrm{x}$ or $\mathrm{y}$, define them.

b) List at least one assumption about the calendar game that your method requires. Explain why this is a reasonable assumption.

c) Give the smallest and the largest value that the sum of four dates can be; explain.
}

\section{Represent}

Math education research suggests that students understand math well when they can explain a math problem using multiple representations. 4 points.

a) Find a way to represent your solution in at least two different ways. You can include them in the Solve section if it makes your write-up shorter, but list the two ways here: Table of values, Graph, Equation, Diagram, Verbal explanation/algorithm.

\section{Solve}

In the Solve stage, you use math techniques to reach an answer. A good answer is efficient, explains the details of your method, can be used by other people, and is generalized-it works in most/all cases, even those that you have not yet tried. 7 points.

a) Discuss your solution method. Giving examples helps make it clearer.

b) What problems, if any, did you encounter that made you want to improve your method?

c) Can the details of your method be taught to other people?

d) Does your method work for a calendar month and year that you have not tried yet?

\section{Interpret}

In the Interpret stage of modeling, you discuss the accuracy and reliability of your method, and you discuss how the question relates to real-world issues. 7 points.

a) Reliability of method. Discuss strengths and weaknesses of your method and your answer. It's important to identify weaknesses; they don't reduce your points unless they are easy to correct.

b) Connections. Think of at least one other game and discuss the mathematical questions that arise from it.

\section{Extend}

If you understand your solution deeply, you will be able to modify it and apply it in a new situation. For the Extend stage of modeling, pose a new, related, and more complex question and answer it mathematically. If you do not answer your question thoroughly, the grade is reduced by 6 points. Creativity is a plus! 6 points.

a) For the Calendar Game, many students create a new game with a different, more difficult pattern of shapes. Or you might follow up on the questions that you identified in other games in the Connections question.

A very ambitious extend answer will earn close to 6 points. Less ambitious answers will earn fewer points.

\section{Figure 2: Sample Task Assignment}

Often a few students in a class will discover the algebraic solution of Sum $=4 \mathrm{x}+16$, where $\mathrm{x}$ stands for the numerically smallest date in the square. However, because this assignment values modeling rather than learning to 
use known models, most students develop an algorithm as their first solution method. For example, one student stated, "Divide the sum by four. With the resulting quotient, add three, subtract three, add four, and subtract four to obtain the four dates." Another student's solution attempted to develop a concrete interpretation for numbers used in the algorithm. The method was to subtract 20 from the sum, "since twenty is the smallest sum you can have on the calendar." The next step was to divide this number by four and add one to the resulting number. "That number represents how many numbers you move over from one....add seven to this number to get the number that goes directly below." Many students find the activity to be intimidating at first, but they often express satisfaction and enjoyment once they realize that the teacher values their creative efforts.

\section{The Five Stage Modeling Assignment: Rationale and Dilemmas}

We have learned a great deal about the problems a teacher faces in creating assignments, communicating expectations, and helping students develop strategies for modeling activities. In this section, we offer commentary on our rationale for our task design, and we reflect on the dilemmas that it poses.

The simplify stage encourages students to make assumptions, and to make their assumptions explicit—an activity that is prominent in earlier modeling task assignments as well. In popular discourse, "making assumptions" tends to have a negative connotation, and so students need assurance that assumptions in problem-solving are valued and necessary. The fundamental issue in modeling task design and grading, that the assignment encourages variability in student solutions, is apparent in this first stage of modeling. Students may develop either equations or algorithms in their first model, and so the assignment guide must allow for this: students may leave part (a) blank if they did not use variables. Another commonplace student reaction is to present a result, such as "Sum $=4 \mathrm{x}+16$," as an assumption. This section of the write-up guide allows instructors to give students feedback on one of the foundations of mathematics as a discipline that results emerge from well-defined assumptions and definitions. We have also found that it is useful to include an exploration question (question c-see Figure 2) in the simplify section that is linked to the particular modeling activity. This is intended to be a "start-up question" to help students develop ability to work with examples, special cases, boundary conditions, or to become aware of processes of measurement.

The represent section responds to widespread research on the value of students displaying their mathematical ideas in a variety of ways (Brenner et al., 1997). This section is designed to encourage reflection on varied ways of communicating ideas to others, and it is also designed to allow students to develop their own authentic form of mathematical thinking - a table of values is just as acceptable as an equation in this stage. This section is not typically problematic for students. They often simply reference representations that they use in other sections of the write-up.

The solve section of the write-up guide begins to contend with the dilemma of representing a cyclic process in a linear format. Students may have completed several revisions of their method, and they should have a means to report and get credit for this effort. Part b (see Figure 2), therefore, asks students to record any revisions that they did to their primary method. This section also introduces a major theme in our modeling class - that a model should be sufficiently detailed that another person can implement it; and that a model must be somewhat generalized. These types of critical reflection are difficult for students and they need substantial guidance to acquire these skills.

The interpret section combines Maaß's (2006) stages of interpretation and validation. The specific questions may be tailored for different activities, but in general, this section aims to have students reflect on the reliability of their method and to evaluate it in terms of related activities outside of the classroom. The reliability question typically asks students to reflect on the efficiency, the strengths and weaknesses of their method. A typical connections question is, "Discuss at least one other real-world situation that requires similar mathematical analysis." These prompts can help students evaluate their solution critically within a wider, realistic context.

Our extend section differs from previous approaches, yet responds to several issues that are at the heart of mathematical modeling: the cyclic process represented in Maaß's (2006) perspective, the need to generalize solutions that is emphasized in the MEA approach, and the need to encourage student creativity and ambition. In our extend section, students must pose a mathematical question related to the original task, and answer it mathematically. In class discussions of the extend phase of modeling, we emphasize the value of creating a more 
generalized answer to the original solution. Students may do this by re-evaluating assumptions, to correct a weakness that they identified in the solve section, or to consider the complexities of different, more complex versions of the original scenario.

However, a student may also pose a question that arose in the course of solving the original task, as long as it is thematically related and more challenging than the original task. In this respect, the extend section departs from existing perspectives on modeling tasks because it is less teacher-directed. Students can get credit in their assignment for pursuing ideas that they themselves create. For example, a young woman extended the Calendar Game by posing a question about the mathematics of football. She asked, "If a football game could go on forever, what numbers would be possible scores?" and stimulated enthusiastic discussion amongst her classmates. This is always an enjoyable portion of the assignment to read and to grade, because it offers surprises for the instructor. It is a significant part of the class structure because it fosters and rewards creativity throughout the semester.

\section{DISCUSSION}

Mathematical modeling, even within the limited context of an algebra class, is a varied and complex learning activity. Modeling can involve a range of specific types of inquiry, such as constructing experiments, algebraic representations, algorithms, or technology-based solutions. It involves cycles of inquiry with a great deal of student choice. Each of the assignment frameworks that we've reviewed responds to these needs differently. We have found that three major dilemmas arise from working with the modeling task assignments, each with possible workarounds that can simplify instructors' entrance into modeling-based teaching.

The first dilemma is to construct an assignment that accounts for the variability of modeling activities. The ARG version, for example, listed experimental and theoretical models directly, under the heading, Explores Relationships: "Relates the problem to existing knowledge, designs appropriate experiments, if necessary, collect and summarizes data, analyses data, constructs empirical and/or theoretical models" (Houston et al., 1994, p. 6). A teacher could instead create a unique task assignment for each model; but thereby loses the chance to convey to students the range of activities that they should master as they conduct mathematical modeling.

The second dilemma is based on the modeling process itself, that students direct themselves through a cycle of revisions. As we have seen, the Open University assignment design focused explicitly on initial and revised models. The ARG assignment design strengthened consistency of grading at the expense of reporting on the students' modeling pathway, but still required students to demonstrate "initiative, determination and flair" (Berry \& Davies, 1996, p. 3.7). Hall (1984) valued students' productive attitude, "drive," but reduced its significance in grading because he found it to be poorly defined. Our own extend section responds to the question of revisions by requiring students to pose and solve a new related question: a generalization of the original problem, or a thematically related question that the student found compelling enough to create for themselves.

Instructors will find that grading the revision stage of a modeling activity is one of the most challenging features of this pedagogy, because students create initial models of differing degrees of generalization. In the Calendar Game example, some students achieve the standard model of Sum $=4 \mathrm{x}+16$ as their first model. Other students may use a verbal algorithm as their initial model, and then present the generalized equation in the extend section. In our approach, both solutions must be accepted as successful submissions with a grade of B or above. The student who offers Sum $=4 \mathrm{x}+16$ as the revised model, however, would receive a lower grade because the revision demonstrates less ambition and complexity, less "drive," because the student has not moved to a more difficult version of the original problem.

A third dilemma modeling instructors will face is being true to the expectations of the discipline. In our perspective, offering students the chance to construct models rather than memorize them is only fair if the teacher accepts variation in student solutions, including approaches that may be less grounded in algebraic symbolism. On the other hand, teachers will not be satisfied if they feel that they are not teaching the subject of algebra. When there is a standard solution, as there is for the Calendar Game or the viewing tubes model, it is not satisfying to a math teacher to complete the activity knowing that many students did not learn the standard solution. Teachers using a modeling approach may feel torn between pedagogical fairness and pedagogical fidelity. 
Staats deals with this dilemma by viewing completion of the modeling assignment, with the initial and extended solutions, as an initial stage in a broader teaching sequence. For example, when students receive their graded Calendar Game model, they also receive a follow-up homework assignment that presents several of their classmate's methods. This allows students to notice the variety of methods that a single problem can inspire in a manner that is conservative of class time. Homework questions ask for proofs that the various methods actually work; this leads to a discussion of the algebraic approach to the model. Once all students have worked on the algebraic method, they can easily handle test questions with novel Calendar Game patterns.

\section{CONCLUSION}

Teachers embarking on a modeling-based algebra class will need to decide clearly whether they wish to focus their students on learning modeling versus learning to use models that are already part of the canon of early undergraduate teaching. Those who accept the challenge of teaching modeling will need to design assignments that respond to modeling as a process, modeling competencies, and developing clarity in academic writing. The assignment design methods reviewed here represent several different teaching values, and taken together, they form substantial resources for undergraduate instructors who are interested in incorporating more open-inquiry projects into their curriculum.

Our own model privileges the modeling process. Students must reflect on the modeling process each time they complete a project. This approach fits our own context for several reasons. First, our class serves many students who are pursuing a degree in elementary education. We believe that it is useful for them to become acquainted with the pedagogical reasoning behind the modeling approach because it is an early introduction to the pedagogies they will learn later in their math methods classes in the University of Minnesota, Department of Curriculum and Instruction. Secondly, our department is deeply committed to multicultural education. The attitude behind the "extend" portion of our rubric requires students to make mathematical choices, and gives them the opportunity to link their mathematical work to their own interests, life experiences, and knowledge. These are key elements of creating a multiculturally appropriate, inclusive educational experience for students. The greatest lesson of all is that the research published on modeling from several decades ago, particularly from the UK and elsewhere in Europe, is highly relevant for today's undergraduate instructors.

\section{AUTHOR INFORMATION}

Susan Staats is an associate professor in the Department of Postsecondary Teaching and Learning in the College of Education and Human Development at the University of Minnesota. She teaches college algebra and interdisciplinary seminars for first year students. Her research interests include designing interdisciplinary learning activities for college algebra and using sociolinguistic methods to understand collaborative mathematics learning. E-mail: staats@umn.edu (Corresponding author)

Douglas Robertson is a professor in the Department of Postsecondary Teaching and Learning in the College of Education and Human Development at the University of Minnesota, where he has been teaching developmental mathematics and computing since 1974. He has a physics B.S. from Purdue University and a mathematics education M.A. and Ph.D. from the University of Minnesota. E-mail: droberts@umn.edu

\section{REFERENCES}

1. Berry, J., \& Davies, A. (1996). Written reports. In C. R. Haines \& S. Dunthorne (Eds.), Mathematical learning and assessment: Sharing innovative practices (pp. 3.3-3.10). London, UK: Arnold.

2. Berry, J., \& Houston, K. (1996). Posters. In C. R. Haines \& S. Dunthorne (Eds.), Mathematical learning and assessment: Sharing innovative practices (pp. 3.12-3.19). London, UK: Arnold.

3. Berry, J., \& Le Masurier, D. (1984). O.U. students do it by themselves. In J. S. Berry, D. N. Burghes, I. D. Huntley, D. J. James, \& A. O. Moscardini (Eds.), Teaching and applying mathematical modelling (pp. 4885). Chichester, UK: Ellis Horwood.

4. Blomhøj, M. \& Jensen, T. (2007). What's all the fuss about competencies? In W. Blum, P. Galbraith, H. Henn, \& M. Niss (Eds), Modelling and applications in mathematics education: The $14^{\text {th }}$ ICMI study (pp. 45-56). New York, NY: Springer. 
5. Brenner, M. E., Mayer, R. E., Moseley, B., Brar, T., Duran, R., Smith Reed, B., \&Webb, D. (1997). The role of multiple representations in learning algebra. American Education Research Journal, 34, 663-689.

6. Burkhardt, H. (1984). Modelling in the classroom: How can we get it to happen? In J. S. Berry, D. N. Burghes, I. D. Huntley, D. J. G. James, \& A. O. Moscardini, (Eds.), Teaching and applying mathematical modelling (pp. 39-47). Chichester, UK: Ellis Horwood.

7. COMAP. (2013). High school mathematical contest in modeling. Retrieved from http://www.comap.com/ highschool/contests/himcm/previous\%20problems.html

8. Complete College America. (2012). Remediation: Higher education's bridge to nowhere. Retrieved from http://www.insidehighered.com/sites/default/server_files/files/CCA\%20Remediation\%20ES\%20FINAL. pdf

9. Crouch, R. M. (1996). Communication. In C. R. Haines \& S. Dunthorne (Eds.), Mathematical learning and assessment: Sharing innovative practices (pp. 3.1-3.31). London, UK: Arnold.

10. Gordon, S. (2008). What's wrong with college algebra? PRIMUS: Problems, Resources, and Issues in Mathematics Undergraduate Studies, 18(6), 516-541.

11. Haines, C., \& Crouch, R. (2007). Mathematical modelling and applications: Ability and competency frameworks. In W. Blum, P. Galbraith, H. Henn, \& M. Niss (Eds), Modeling and applications in mathematics education: The $14^{\text {th }}$ ICMI study (pp. 417-424). New York, NY: Springer.

12. Haines, C., \& Houston, K. (2001). Assessing student project work. In D. Holton (Ed.), Teaching and learning mathematics at university level (pp. 431-442). Dorderecht: Kluwer.

13. Hall, G. (1984). Assessment of modelling projects. In J. S. Berry, D. N. Burghes, I. D. Huntley, D. J. G. James, \& A. O. Moscardini (Eds.), Teaching and applying mathematical modelling (pp. 143-148). Chichester, UK: Ellis Horwood.

14. Herriott, S., \& Dunbar, S. (2009). Who takes college algebra? PRIMUS: Problems, Resources, and Issues in Mathematics Undergraduate Studies, 19(1), 74-87.

15. Houston, S. K., Haines, C. R., \& Kitchen, A. (1994). Developing rating scales for undergraduate mathematics projects. Coleraine, Northern Ireland: University of Ulster.

16. Le Masurier, D., \& Crouch, R. M. (1996). Oral presentations. In C.R. Haines \& S. Dunthorne (Eds.), Mathematical learning and assessment: Sharing innovative practices (pp. 3.20-3.31). London, UK: Arnold.

17. Lesh, R., Cramer, K., Doerr, H., Post, T., \& Zawojewski, J. (2003). Model development sequences. In R. Lesh \& H. Doerr (Eds.), Beyond constructivism: Models and modeling perspectives on mathematics problem solving, learning, and teaching (pp. 35-58). Mahwah, NJ: Lawrence Erlbaum.

18. Maaß, K. (2006). What are modelling competencies? ZDM, 38(2), 113-142.

19. Mason, J. (1984). Modelling: What do we really want students to learn? In J. S. Berry, D. N. Burghes, I. D. Huntley, D. J. G. James, \& A. O. Moscardini (Eds.). Teaching and applying mathematical modelling (pp. 215-234). Chichester, UK: Ellis Horwood.

20. Open University. (1981). MST204 project guide for mathematical modeling and methods. Milton Keynes: Open University.

21. Purdue University School of Engineering. (2013). Small group mathematical modeling. Retrieved from https://engineering.purdue.edu/ENE/Research/SGMM/MEAs_html

22. Rockswold, G. (2009). College algebra with modeling and visualization. Boston, MA: Pearson.

23. Small, D. (2002). An urgent call to improve traditional college algebra programs. Retrieved from http://toyama45.maa.org/t_and_1/urgent_call.html

24. Small, D. B. (2006). College algebra: A course in crisis. In N. Baxter, N. Hastings, F. Gordon, S. Gordon, \& J. Narayan (Eds.), A fresh start for collegiate mathematics: Rethinking the courses below calculus (pp. 83-89). Washington, D.C.: Mathematical Association of America.

25. Timmons, D., Johnson, C., \& McCook, S. (2008). Fundamentals of algebraic modeling: An introduction to mathematical modeling with algebra and statistics. Belmont, CA: Brooks/Cole. University of Minnesota. (n.d.). MEA Library. Retrieved from https://moodle2.umn.edu/course/view.php?id=8332

26. University of Minnesota. (n.d.). 
NOTES 